\title{
A FORMAÇÃO PARA A CIDADANIA NO ENSINO SUPERIOR
}

\author{
Antônio Carlos Will Ludwig \\ Pós-Doutorado pela Universidade de São Paulo (USP) \\ emil@linkway.com.br
}

\begin{abstract}
Resumo
O presente artigo trata da formação de estudantes universitários para o exercício da cidadania. Ele tem por objetivo apresentar os procedimentos empregados por universidades em tal formação. Esta apresentação baseia-se no ensino superior dos Estados Unidos da América do Norte, da Europa e do Brasil. A principal conclusão alcançada é a de que em universidades destas três localidades são utilizados procedimentos bastante apropriados e efetivos.
\end{abstract}

Palavras Chave: Cidadania Ativa. Ensino Superior. Formação Para a Cidadania.

\section{CITIZENSHIP TRAINING IN HIGHER EDUCATION}

\begin{abstract}
This article deals with the formation of university students for the exercise of citizenship. It aims to present the procedures employed by universities in such training. This presentation is based on higher education in the United States of North America, Europe and Brazil. The main conclusion reached is that, in universities of these three localities, very appropriate and effective procedures are used.
\end{abstract}

Key Words: Active Citizenship. Higher Education. Citizenship Training.

\section{FORMACIÓN PARA LA CIUDADANÍA EN LA EDUCACIÓN SUPERIOR}

\section{Resumen}

Este artículo trata sobre la formación de estudiantes universitarios para el ejercicio de la ciudadanía. $\mathrm{Su}$ objetivo es presentar los procedimientos empleados por las universidades en dicha formación. Esta presentación se basa en la educación superior en los Estados Unidos de América del Norte, Europa y Brasil. La principal conclusión a la que se llegó es que, en las universidades de estas tres localidades, se utilizan procedimientos muy adecuados y eficaces.

Palabras Clave: Ciudadanía Activa. Educación Superior. Educación Para La Ciudadanía. 


\section{INTRODUÇÃO}

O trabalho em pauta é resultante de uma pesquisa bibliográfica, ou seja, ele foi elaborado após o exame, avaliação e fichamento de uma considerável quantidade de textos relativos ao assunto. Após a sua concretização foi possível, de imediato, notar que em se tratando da abordagem relativa à formação para a cidadania tanto no âmbito da educação informal quanto na educação formal e nesta ema qualquer um de seus níveis, ou seja, o fundamental, o médio e o superior, é possível vislumbrá-la de duas maneiras. Uma delas faz referência à elaboração de propostas voltadas ao preparo do cidadão nas quais o conceito de cidadania não é devidamente explicitado e sim apenas pressuposto ou subentendido e a outra, ao contrário, leva em conta como base da proposta um conceito de cidadania exposto de maneira clara e inteligível. No caso em pauta a formação para a cidadania no ensino universitário será abordada de acordo com a segunda maneira.

O estabelecimento do significado de cidadania nesta abordagem requer a feitura de um breve exame para justificar a opção assumida. Inicialmente vale colocar que do ponto de vista jurídico a cidadania diz respeito a uma relação entre dois entes: o indivíduo e o Estado. Nesta relação o indivíduo tem de cumprir uma série deveres para com o Estado tais como pagar impostos e prestar o serviço militar, e este tem que proporcionar um conjunto de direitos ao indivíduo tais como a educação e a saúde. Embora esta relação tenha um caráter funcional nem sempre ela encontra-se livre de certos percalços, pois tanto o indivíduo quanto o Estado podem deixar de realizar de modo parcial ou total suas obrigações. Apesar que nesta possibilidade só é possível conceber a cidadania no âmbito do regime democrático o qual é sustentado pelo princípio da soberania popular.

Não obstante este significado de cidadania seja amplamente aceito e concretizado em todos os países democráticos ele não esgota o entendimento a seu respeito. Assim sendo, cabe lembrar que a noção exposta é de cunho liberal. Além de tal ideia existem as concepções pós-moderna, comunitarista e marxista. Uma diferença separa o ponto de vista liberal dos demais. Na versão liberal o cidadão é visto como um ser predominantemente passivo enquanto que nas demais interpretações ele é tratado como um indivíduo predominantemente ativo.

Levando em conta esta diferença pode ser dito que o cidadão passivo refere-se à pessoa que por determinados motivos prefere realizar sua existência, de modo prevalente, no âmbito da esfera privada que é o setor restrito e reservado da vida em sociedade onde valem os interesses particulares, onde prevalece a exigência da sobrevivência, onde a intimidade se concretiza e onde a visibilidade e a transparência se encontra reduzida ao

Cidadania em Ação: Revista de Extensão e Cultura, Florianópolis (SC), v.4, n.2, jul./dez. 2019. 
máximo possível. Esta esfera inclui alguns espaços existentes na comunidade tais como o local de trabalho e a vida familiar. Além de ter o costume de cumprir seus deveres para com o Estado ele também aceita ser governado por outros.

Por sua vez considera-se que o cidadão ativo é o indivíduo que se julga governante. Além de estar inserido na esfera privada, realizar as atividades do cidadão passivo e cumprir suas obrigações para com o Estado frequentemente encontra-se presente na esfera pública que é o setor da vida em sociedade acessível a todas as pessoas, onde predomina o interesse geral e a visibilidade e a transparência são ampliadas até os seus limites. Nela valem o diálogo, a comunicação, o discurso, a argumentação e a ação conjunta que pode se voltar para o objetivo de influenciar as decisões políticas. Esta esfera inclui certos espaços sociais tais como as ruas e as praças onde assuntos que se relacionam com a vida de todos são examinados e debatidos.

Este tipo de cidadão além de lutar pelos seus direitos e interesses costuma realizar ações individuais e grupais em benefício da coletividade, principalmente aquelas relacionadas aos direitos outorgados e prioritariamente as que favorecem os segmentos desprivilegiados da sociedade. Ele não admite comportar-se apenas como uma pessoa governada pois também almeja ser governante. Como pode ser percebido este conceito de cidadania ultrapassa a mera relação jurídica entre o indivíduo e o Estado, embora não a negue. Observe-se também que estes dois tipos de cidadão não são excludentes porquanto inexiste qualquer fator capaz e impedir que o passivo se torne ativo e o ativo se torne passivo. Note-se ainda que as esferas privada e pública não se apresentam de modo estanque haja vista que podem ocorrer intersecções entre elas. Sua ação, sempre consoante ao regime democrático, pode ser local, regional estadual, nacional e também internacional porquanto o espaço de participação disponível encontra-se globalizado. É esta concepção de cidadania ativa que será aqui utilizada.

\section{ESTADOS UNIDOS DA AMÉRICA DO NORTE}

Os norte americanos, assim como os europeus, tal como veremos mais à frente, desde há muito tempo vêm se preocupando com a educação para o exercício da cidadania em todos os níveis de ensino. Essa preocupação remonta aos primórdios do século vinte quando as matrículas nas escolas secundárias cresceram exponencialmente. Tal crescimento ensejou a ideia de criação de um currículo diferenciado em substituição ao anterior de cunho elitista voltado para a preparação ao ensino superior. Ao lado da formação para o mercado de trabalho ele visava também o preparo para o exercício da cidadania. Esta nova visão dirigida

Cidadania em Ação: Revista de Extensão e Cultura, Florianópolis (SC), v.4, n.2, jul./dez. 2019. 
para a eficiência social e a formação do caráter substituiu a proposta de doutrinação moral e religiosa que vigorou até o início deste século.

Ela continuou na década de cinquenta quando o então presidente do país, Dwight Eisenhower, estimulou e financiou um debate sobre os objetivos da educação nacional. Em consequência líderes civis e empresariais elaboraram uma lista de quinze metas para o ensino público dentre as quais se encontravam o patriotismo e a boa cidadania (LUDWIG, 2019). Na década de sessenta surgiu um movimento contrário à dominante formação moral e cívica do aluno e favorável à uma concepção democrática baseada nas teorias relativas à clarificação de valores e do desenvolvimento moral.

A elevada influência da ideologia neoliberal em fins deste século teve o poder de potencializar a preocupação já existente de preparar os jovens para obtenção do sucesso profissional e debilitar as abordagens de cunho democrático. Em seu lugar reemergiu a proposta de educação do caráter oriunda dos setores conservadores da sociedade norte americana. Apesar da pressão feita sobre os alunos com vistas ao mercado de trabalho e da ofensiva conservadora desejosa de inculcar valores tradicionais, a escola norte americana, particularmente a que cuida do ensino médio, a ‘high school’, não perdeu seu caráter liberal.

Nos dias que passam é bem notório que a formação para o exercício da cidadania ativa ocorre nas aulas de civismo e governo (LUDWIG, 2019). Quanto a elas sabe-se que nas escolas de todos os estados é exigido o ensino desses assuntos. Embora predomine a atividade teórica, os alunos muitas vezes realizam serviços comunitários, simulações de processos democráticos, discussões críticas de eventos atuais, estudos de casos recentes abordados pela Suprema Corte, preparação para audiências simuladas no Congresso, identificação e resolução de problemas com base em políticas públicas, formulação e concretização de projetos proporcionadores de melhorias para as escolas e a comunidade e reuniões com as autoridades dos condados para debater soluções beneficiadoras da coletividade. Cabe destacar que desde 2015 o ensino de cidadania, em muitos Estados, é avaliado periodicamente por meio do programa de Avaliação Nacional do Progresso Educacional (LUDWIG, 2019). Diversos Estados exigem que os alunos sejam aprovados no exame de cidadania para obterem o certificado de conclusão do ensino médio.

O estado atual do ensino de cidadania pode ser verificado nos relatórios periódicos elaborados pela Education Commission of the States e pelo National Center of Learning and Civic Engagement, os quais são responsáveis pelas revisões de leis e documentos e inspeções curriculares. Um dos mais recentes, publicado em 2016, sob o título 50-State Comparison: Civic Education Policies apresenta as seguintes inferências: quarenta e oito Estados tratam

Cidadania em Ação: Revista de Extensão e Cultura, Florianópolis (SC), v.4, n.2, jul./dez. 2019. 
da educação para a cidadania em documentos oficiais; todos os Estados exigem que o alunos realizem cursos em educação cívica para se formarem; trinta e sete Estados exigem que os alunos demonstrem proficiência em educação cívica; a totalidade dos Estados inclui aprendizagem cívica nas grades curriculares.

Westheimer (2015) assevera que as escolas norte americanas estão contribuindo para a formação de três tipos de cidadãos: o pessoalmente responsável, o participativo e o orientado para a justiça social. O pessoalmente responsável é aquele que se voluntaria para auxiliar as pessoas mais necessitadas, o participativo é aquele que se envolve com a vida social da comunidade em seus diversos níveis e o orientado para a justiça social é aquele bem informado, que pensa de modo independente, que é versado em assuntos sociais complexos e em decorrência atua de diversas maneiras para melhorar a sociedade.

Uma das mais importantes atividades responsáveis pela formação do cidadão ativo é o trabalho voluntário. De acordo com Edwards (2001) e colaboradores, aproximadamente cem milhões de estadunidenses foram em 1998, representando um aumento de quase quatorze por cento em relação ao ano anterior. Esta força de trabalho espontânea proporcionou mais de dezenove bilhões de horas de labor não remunerado ao país. Segundo eles a ação voluntária dos norte americanos tende a diminuir na transição da adolescência para a idade adulta. O pico mais elevado se situa na faixa dos trinta e cinco a cinquenta e cinco anos. Os denominados serviços diretos tais como servir comida e fornecer trabalho de transporte são os mais frequentes. É notório que os mais idosos preferem os serviços indiretos, ou seja, funções administrativas e tarefas de angariação de fundos.

Alguns dados estatísticos mais atuais referentes aos anos de 2002 a 2005 apresentados por Dote (2006) e colaboradores apontam que o voluntariado de estudantes universitários teve um aumento de mais ou menos vinte por cento. A taxa de alunos das faculdades envolvidos com atividades voluntárias, em torno de trinta por cento excedeu a taxa de voluntários da população adulta geral em dois por cento. As atividades voluntárias mais comuns dizem respeito à tutoria e orientação de jovens com a cifra de vinte e seis por cento e a prestação de serviços em organizações religiosas com vinte e três por cento. Vinte e sete por cento dos estudantes universitários se apresentam como voluntários esporádicos enquanto que quarenta e quatro por cento se revelam voluntários regulares.

Outra atividade tão ou mais relevante que o trabalho voluntário diz respeito ao denominado service learning ou aprendizado de serviço, um expediente criado, desenvolvido e aperfeiçoado pelos estadunidenses. (LUDWIG, 2019). Seu ponto de partida ocorreu na década de vinte do século passado com a criação de um programa de ação

Cidadania em Ação: Revista de Extensão e Cultura, Florianópolis (SC), v.4, n.2, jul./dez. 2019. 
comunitária estudantil no Antioch College baseado nas concepções de John Dewey. O avanço desse programa foi bastante influenciado pelas ideias de Paulo Freire cinquenta anos depois por ocasião de seu exílio político. Sua forma atual foi posta em prática pela primeira vez em 1967 na Oak Ridge Associated Universities e se consolidou dois anos após pela celebrização da primeira Service-Learning Conference.

Apoiando-se nas assertivas de Naval (2010) e colaboradores podemos entender o service learning como uma proposta complexa que envolve as concepções de necessidades sociais, trabalho na comunidade, aprendizagem curricular, participação, cooperação, reflexão e parceria. Os autores destacam que ele sempre se inicia com um exercício de exame da realidade para determinar o tipo de intervenção mais apropriado. Comentam que do ponto de vista pedagógico o service learning é uma metodologia centrada no aluno a qual requer a sua intensa participação. Realçam também que o mesmo se mostra como uma atividade caracteristicamente grupal cuja cooperação normalmente envolve as pessoas que estão sendo ajudadas bem como requer o estabelecimento de parcerias entre instituições.

A partir da década de setenta cresceu de modo significativo o movimento a favor do service learning não só na educação superior como também no ensino médio. Vale lembrar que desde a década de noventa cursos da área da saúde tais como odontologia e enfermagem, notoriamente, têm se mostrado inclinados ao exercício do service learning. A força desse movimento encontrou sua manifestação mais expressiva na experiência do Campus Compact, uma aliança nacional formada por mais de mil Colleges e Universities públicas e privadas com o envolvimento de milhões de alunos.

Segundo Tapia (2010), os dirigentes destas instituições educativas revelaram uma conduta de comprometimento com o sucesso da missão cívica da educação superior. Para tanto se empenharam em fomentar a prestação de serviços à comunidade com a massiva ajuda dos estudantes que em retorno adquiriram disposições e habilidades cívicas consequentes do intercâmbio entre os campi e seus respectivos entornos. De acordo com a autora o plano estratégico desta aliança nacional inclui cinco metas a serem alcançadas: parceria com o governo para estimular o cumprimento do compromisso cívico do ensino superior; aprofundamento da compreensão da universidade como uma instituição comprometida com a responsabilidade cívica; incremento da quantidade e da qualidade do service learning e do compromisso cívico dos membros do Campus Compact; fortalecimento do compromisso cívico entre a comunidade e as faculdades e incremento à capacidade organizativa do Campus em nível nacional e estatal com vistas a torná-lo um líder indiscutível da educação cívica.

Cidadania em Ação: Revista de Extensão e Cultura, Florianópolis (SC), v.4, n.2, jul./dez. 2019. 


\section{CONTINENTE EUROPEU}

A Comunidade Europeia dos dias atuais, composta por vários países, é consequência de um longo processo histórico. Examinando-se a constituição dos mesmos no desenrolar do tempo constata-se que muitos deles demoraram bastante para adquirir a feição que hoje apresentam. Veja-se, por exemplo, o caso da Itália que na Idade Média encontrava-se dividida em pequenas repúblicas, ducados e Estados Pontifícios. A França também permaneceu fracionada em ducados, condados e grandes feudos durante um lapso considerável. Portanto, o que se verifica, é que os países que hoje a integram se constituíram em Estados Nacionais após a decorrência de alguns séculos e graças à institucionalização da centralização política (PINSKY, 2003).

Parece óbvio então que a Comunidade Europeia só pode emergir devido a presença de Estados Nacionais sedimentados. De modo parecido ao surgimento de cada um desses países, o estabelecimento de tal comunidade exigiu a implantação de determinados órgãos capazes de garantir a sua existência tais como o Parlamento Europeu que se volta para a confecção das leis europeias e pela aprovação do orçamento europeu; o Banco Central Europeu que é responsável pela moeda única, ou seja, o euro, pela manutenção da estabilidade dos preços e pela administração das reservas de divisas depositadas pelos países membros dentre outras tarefas relevantes; o Mercado Comum Europeu que promove a livre circulação de bens, capital, pessoas e serviços e o Tribunal de Justiça da União Europeia que por ser a instância mais elevada tem jurisdição sobre matérias relativas à interpretação das leis europeias.

Assim como houve em cada um dos Estados antes do processo de integração neste seleto grupo se empenhou para manter a sua unidade e perenidade, o mesmo verifica-se em relação à Comunidade Europeia. Com efeito, é grande a preocupação de seus dirigentes para sustentar a coesão das nações que dela fazem parte. É esta coesão que tenta garantir a permanência de todos no bloco supranacional e evitar o possível desligamento de qualquer um deles no decorrer do tempo. A educação foi eleita pelos dirigentes de tal comunidade como um dos fatores essenciais para a manutenção desta coesão (LUDWIG, 2009).

De fato, no início da última década do século passado veio à tona uma resolução do Conselho de Ministros com vistas a alcançar o objetivo de fortalecer a mentalidade dos jovens no que diz respeito ao afeto de pertencimento à Europa bem como de intensificar o seu desejo de protagonizar ações favoráveis à construção da Comunidade Europeia. $\mathrm{O}$ denominado Processo de Bolonha (ARAÚJO; SILVA; DURÃES, 2018), consequente da reunião de um grupo de ministros em 1999 estabeleceu que a tarefa de forjar uma Europa

Cidadania em Ação: Revista de Extensão e Cultura, Florianópolis (SC), v.4, n.2, jul./dez. 2019. 
unida e forte depende muito de um ensino superior voltado para a pesquisa inovadora. A chamada Estratégia de Lisboa (RODRIGUES, 2003) resultante de uma reunião do Conselho Europeu de Lisboa em 2000 instituiu que a manutenção da coesão social europeia depende muito do investimento nas pessoas, na capacitação delas, na formação do capital humano. A intitulada Estratégia Europa 2020 (LUDWIG, 2019) que emergiu em 2011 apresentou cinco objetivos essenciais a serem perseguidos sendo um deles o relativo à melhoria dos níveis de educação e de redução da taxa de abandono escolar. Tal objetivo se encontra intimamente ligado ao anseio de preservação da coesão social e territorial da Comunidade Europeia.

Há um aspecto da área da educação que pela sua relevância é bastante valorizado pelos dirigentes europeus, ou seja, o processo de formação para o exercício da cidadania em nível local, regional, nacional e internacional que acontece tanto na educação básica quanto na superior. Esta formação é muito importante para tais dirigentes porque têm como certo que ela contribui significativamente para a manutenção da estabilidade social em todos os países que integram a Comunidade Europeia, uma ocorrência fundamental para a sua preservação no decorrer do tempo.

No primeiro relatório elaborado pela Rede Eurydice intitulado "A Educação Para a Cidadania Nas Escolas da Europa”, publicado em 2005 encontra-se escrito no prefácio (p.3) que a Comissão Europeia "identifica claramente o desenvolvimento da cidadania europeia como uma das principais prioridades da actuação da União Europeia". Por meio do programa Cidadãos Para a Europa almeja-se estimular o envolvimento ativo dos europeus "no processo de integração europeia e desenvolver entre eles um sentimento de pertença e de identidade europeias". Tem por meta este programa fazer com que os europeus internalizem os sentimentos de tolerância e solidariedade e se transformem em "cidadãos responsáveis e activos".

Logo após o prefácio aparece o tópico relativo à introdução. (p. 7) Nela os organizadores do relatório informam que o mesmo é resultante de uma pesquisa que envolveu trinta países integrantes da Rede Eurydice e que teve por escopo examinar "a forma como a educação para a cidadania é ensinada nas escolas". Destacam que "foi dada especial atenção à contribuição da educação para a coesão social através de actividades destinadas a promover a cidadania activa”. Observe-se que se trata de um estudo que teve por objeto o ensino primário e secundário inferior e superior, os quais correspondem ao nosso ensino fundamental e médio.

O segundo relatório divulgado em 2012 traz no preâmbulo (p.3) a assertiva de que os cidadãos europeus precisam intervir "na vida política e social não só para assegurar o

Cidadania em Ação: Revista de Extensão e Cultura, Florianópolis (SC), v.4, n.2, jul./dez. 2019. 
desenvolvimento dos valores democráticos fundamentais, mas também para fomentar a coesão social numa época de crescente diversidade social e cultural". Traz também a afirmação de que este ato de ingerência depende da aquisição de determinados conhecimentos, competências e atitudes que são fomentados pelo processo educativo. Acrescenta ainda que a promoção "da cidadania ativa através da educação escolar constitui igualmente um dos principais objetivos do atual quadro estratégico para a cooperação europeia no domínio da educação e da formação, em vigor até 2020”.

$\mathrm{Na}$ introdução (p.7) encontra-se escrito que o relatório em questão "procura descrever a forma como as políticas e as medidas relativas à educação para a cidadania tem vindo a evoluir nos países europeus, nos últimos anos", particularmente em relação aos “31 países da Rede Eurydice".

Quanto ao terceiro e último relatório, datado de 2017 e elaborado de modo sintético, se encontra escrito logo em seu início (p.3) que os dados apresentados "baseiam-se nas regulamentações e recomendações existentes reunidas pela Rede Eurydice em 42 sistemas educativos, complementados pela literatura académica e por entrevistas com atores relevantes a nível nacional". Com outras palavras ele repete o que se encontra escrito nos dois anteriores. Com efeito, ao se referir ao objetivo da educação para a cidadania se encontra mencionada a pretensão de promover a "coexistência harmoniosa e o fomento do desenvolvimento mutuamente benéfico dos indivíduos e das comunidades em que se integram". Uma das conclusões mais importantes que nele consta é a de que "Todos os países contam com programas curriculares ambiciosos que visam desenvolver certas competências que permitem interagir eficaz e construtivamente com os outros, atuar de maneira socialmente responsável, agir democraticamente e desenvolver um espírito crítico". No que diz respeito ao ensino superior, objeto central deste trabalho, constata-se que a educação para a cidadania continua sendo nele perseguida. Entretanto outras preocupações acompanham esta perseguição, as quais podem ser detectadas no decorrer de sua evolução histórica, particularmente em relação ao final do século passado e início do atual. Tais preocupações decorrem do fato de que desde os primórdios da década de noventa até os dias atuais a formação universitária se encontra intimamente atrelada às políticas neoliberais.

Em função de tais políticas emergiu, conforme vimos, um dos primeiros marcos da reestruturação do ensino superior europeu, ou seja, o intitulado Processo de Bolonha que resultou de uma reunião de ministros da educação. Neste encontro tais dirigentes chegaram à conclusão de que a educação universitária europeia deveria se rivalizar com outras de

Cidadania em Ação: Revista de Extensão e Cultura, Florianópolis (SC), v.4, n.2, jul./dez. 2019. 
vários países do mundo, principalmente com a norte americana; deveria ser capaz de contribuir decisivamente para o processo de inovação e preparar os estudantes para se incorporarem ao competitivo mercado de trabalho global.

Tendo em vista a inclusão dos jovens no mundo do emprego a Comissão Europeia aventou uma relação das competências que precisariam desenvolver. Observe-se que a competência deve ser entendida segundo a concepção de Perrenoud (2005), um dos principais influenciadores da educação europeia. De acordo com ele a competência é conceituada como uma capacidade de mobilizar vários recursos cognitivos para enfrentar determinadas situações. Em harmonia a esta definição o Conselho Europeu, por meio de uma resolução datada de 2002 (CHIZZOTTI ; CASALI, 2012) apresentou um conjunto de oito competências válidas também para o ensino básico: comunicação em língua materna, comunicação em línguas estrangeiras, competência matemática e competências básicas em ciência e tecnologia, competência digital, aprender a aprender, sentido de iniciativa e espírito empreendedor, consciência e expressão culturais e competências sociais e cívicas.

Cada uma dessas competências foi devidamente conceituada no Anexo da Recomendação do Parlamento Europeu e do Conselho da União Europeia em 2006. No que diz respeito às competências sociais e cívicas, as quais constituem a referência principal neste escrito, estas receberam o significado de atributos agregadores das capacidades "pessoais, interpessoais, e interculturais que permitem ao indivíduo participar de forma eficaz e construtiva na vida social e laboral, em particular em sociedades cada vez mais heterogêneas, e resolver conflitos quando necessário. As competências cívicas permitem ao indivíduo participar plenamente na vida cívica com base no conhecimento dos conceitos e das estruturas sociais e políticas e ter uma participação cívica, ativa e democrática" (CHIZZOTTI; CASALI, 2012)

Hoskins (2010), um dos mais proeminentes estudiosos da educação para a cidadania e inspirador de sua prática na Comunidade Europeia, em um de seus artigos apresentou mais esclarecimentos sobre a competência cívica no qual destaca que a "participação na sociedade civil, comunidade e/ou vida política [é] caracterizada pelo respeito mútuo e não violência de acordo com os direitos humanos e a democracia”.

Neste mesmo artigo Hoskins cita uma recomendação da Comissão Europeia a qual assevera que "a competência cívica baseia-se no conhecimento dos conceitos de democracia, justiça, igualdade, cidadania e direitos civis, inclui o conhecimento de eventos contemporâneos, bem como os principais eventos e tendências da história nacional, europeia e mundial". Ele realça que tal competência agrega as habilidades "de se envolver

Cidadania em Ação: Revista de Extensão e Cultura, Florianópolis (SC), v.4, n.2, jul./dez. 2019. 
efetivamente com outras pessoas no domínio público e [de] demonstrar solidariedade e interesse na solução de problemas que afetam a comunidade local e a comunidade em geral". Ainda neste artigo ele apresenta um programa educacional destinado a preparar o cidadão ativo que envolve os níveis cognitivo, afetivo e procedimental. No nível cognitivo Hoskins inclui os conhecimentos de direitos humanos, diversidade, herança cultural e temas atuais. No nível afetivo inclui as atitudes de autonomia, interesse pela política, resiliência, respeito pelas outras culturas e pela opinião divergente e os valores democracia, igualdade de gênero, sustentabilidade, justiça, equidade e paz. No nível procedimental inclui as capacidades de resolver problemas e conflitos, de pesquisar, de refletir criticamente, de comunicar, de debater, de ouvir atentamente e de lidar com a ambiguidade.

Embora a partir de 2006 possam ter ocorrido transformações no ensino superior europeu estas competências continuam firmes a balizá-lo até os dias de hoje. Vale destacar que já foi publicado um relatório produzido pela Rede Eurydice em 2012 pertinente ao desenvolvimento dessas competências no âmbito dos países que integram a Comunidade Europeia.

Segundo tal relatório aproximadamente metade dos países que fazem parte da Comunidade Europeia desenvolvem estratégias nacionais para as competências sociais e cívicas. Nestas estratégias o enfoque no ensino pode se voltar para uma determinada matéria, se direcionar para uma área de aprendizagem ou caminhar rumo a todo o currículo. Elas também podem se limitar à uma etapa da educação, abarcar todos os níveis do sistema educativo ou estender-se ao conjunto da sociedade. São ainda avaliadas periodicamente mediante provas nacionais estandardizadas.

De acordo com Watson (2011) e colaboradores diversas universidades europeias, bem como muitas norte americanas, latino americanas, africanas e outras de vários recantos do mundo se encontram desenvolvendo atividades de engajamento cívico. Todas se mantêm empenhadas em mobilizar seus recursos humanos para atender aos interesses e necessidades prioritários das comunidades onde estão inseridas e preparar seus alunos para liderarem com processos de transformação. Para tanto, apoiam e incentivam o trabalho voluntário, o serviço comunitário, a pesquisa aplicada, os projetos de desenvolvimento local e se preocupam com os impactos sociais provocados por estas práticas institucionais. Destinam funcionários para exercerem atividades de apoio e investem significativamente na capacitação dos professores que levam adiante tais ações.

No que diz respeito ao trabalho voluntário nota-se que o incentivo à sua prática no ensino universitário tem sido capaz de provocar a sua continuação após o término do curso

Cidadania em Ação: Revista de Extensão e Cultura, Florianópolis (SC), v.4, n.2, jul./dez. 2019. 
em uma parcela significativa de estudantes. Segundo Bolseira (2014), no continente europeu este tipo de atividade é mais frequente em indivíduos com elevados níveis de escolaridade. Ela menciona que em Portugal aproximadamente quinzes por cento dos voluntários possuem curso superior. É o percentual mais elevado entre todos os grupos que se dedicam a concretizá-lo. Cita ainda que as dezenas de organizações voltadas para o trabalho voluntário possuem em seus quadros perto de setenta por cento de indivíduos que concluíram a educação superior. Embora tal ofício possua uma conotação eminentemente cívica ele também é socialmente valorizado porque contribui para o desenvolvimento de várias competências dos voluntários. Além disso, proporciona uma ajuda de quatro centenas de milhões de dólares à economia e favorece sobremaneira a estratégia de crescimento da Europa.

O Fundo Comunitário de Educação Superior da Inglaterra destinou para os anos de 2002 a 2006 trinta e sete milhões de libras esterlinas ao projeto de ampliação das oportunidades de voluntariado no setor universitário. (HOLDSWORTH; QUINN, 2010). Nesta época o Departamento de Educação e Competências elaborou e concretizou propostas voltadas para a capacitação dos estudantes que desenvolveram atividades em suas comunidades. Estes autores mencionaram que em 2002 uma pesquisa revelou que em quatro instituições universitárias quinze por cento de seus estudantes estavam envolvidos com trabalho voluntário. Outra investigação mostrou que em 2003 mais de quarenta mil discentes se encontravam atuando como voluntários. Afirmaram também que as instituições de ensino superior da região nordeste do país encaminham seus alunos para a prática do voluntariado em áreas urbanas desfavorecidas e as da região sudoeste os dirigem para os ambientes rurais.

As universidades europeias estão utilizando também o denominado service learning como um importante recurso de formação para a cidadania o qual conforme vimos é uma criação norte americana. O interesse das instituições superiores de ensino para com este recurso fortaleceu-se significativamente porque além de sua relevância cívica ele tem se mostrado eficiente em relação ao aumento da aprendizagem dos alunos. De acordo com Warren (2012), uma pesquisa realizada em 2007 evidenciou que a aprendizagem de serviço tem uma influência positiva nos resultados de aprendizagem discente.

Quanto ao uso desse recurso Schlierf (2010) menciona como exemplos a Universidade de Sevilla na Espanha que há vários anos vem desenvolvendo um projeto denominado Arquitetura e Compromisso Social que se volta para uma investigação participativa atinente ao planejamento urbano e a Universidade Técnica da Dinamarca que conduz um programa de produção de alimentos ecológicos em parceria com grupos

Cidadania em Ação: Revista de Extensão e Cultura, Florianópolis (SC), v.4, n.2, jul./dez. 2019. 
comunitários. Outro exemplo se encontra na Universidade de Évora em Portugal. Este exemplo aparece no texto de Freire (2017) e colaboradoras e diz respeito a um projeto de arquitetura paisagística desenvolvido para uma associação de solidariedade social.

Além do trabalho voluntário e do service learning, algumas universidades adotam outros procedimentos. Quatro iniciativas foram postas em prática em instituições de ensino superior inglesas (MCCOWAN, 2012). Na East London University foi instituído um curso online sobre instituições políticas e processos constitucionais com o objetivo de incentivar o envolvimento ativo do aluno em questões políticas. Na Midilands University ocorreu a oferta de um módulo ministrado por dois palestrantes da área de Ciência Política com vistas a fazer com que os discentes tivessem a oportunidade de refletir sobre a natureza da cidadania contemporânea, produzissem insights sobre a natureza do ativismo político e desenvolvessem atributos pessoais requeridos para a cidadania ativa. Tal módulo previu o emprego de discursos simulados, debates parlamentares simulados e discussões em pequenos grupos. Na Greater London University emergiu um conjunto de atividades composta por palestras, seminários e debates com a finalidade de instar os alunos a refletirem sobre suas relações com as comunidades locais, nacionais e internacionais. Na Southern University o curso desenvolvido tratou de questões relativas a direitos e responsabilidades, sensibilidade cultural, justiça social e empregabilidade na economia globalizada tendo por escopo a transformação dos alunos em líderes da mudança social.

Por sua vez, universidades irlandesas estimulam a participação dos alunos em governança compartilhada (BOLAND, 2005). Segundo seus dirigentes esta forma de gestão é considerada como um exercício cívico de fundamental importância para a democracia. Eles consideram, entretanto, que a governança compartilhada é uma condição necessária, porém insuficiente para a realização do ideal democrático. Acreditam que a mencionada participação se constitui em uma oportunidade singular e relevante para praticar e nutrir os hábitos da vida democrática. Supõem que a democracia acadêmica se mostra como uma précondição significativa para a realização da democracia política dentro das instituições de ensino superior.

\section{BRASIL}

Em nosso país, o processo de formação para a cidadania, ao contrário do que ocorre nos Estados Unidos e na Europa, não constitui uma preocupação mais ampla, isto é, que é própria de grandes contingentes de educadores, políticos e autoridades dirigentes de órgãos responsáveis pela educação em seus diversos níveis, apesar da Constituição Federal (art.

Cidadania em Ação: Revista de Extensão e Cultura, Florianópolis (SC), v.4, n.2, jul./dez. 2019. 
205) determinar que cabe às escolas do ensino fundamental, médio e superior dedicarem-se ao preparo dos jovens para o seu exercício, determinação esta que se encontra referendada na Lei de Diretrizes e Bases da Educação Nacional (art. $2^{\circ}$ ). Também não existem políticas educacionais apropriadas voltadas para o preparo do cidadão e, consequentemente, nem estratégias pedagógicas específicas delineadas para este mister.

No entanto existem alguns expedientes nas escolas da educação básica que contribuem para o preparo do aluno com vistas ao exercício da cidadania. Um deles diz respeito aos conselhos de classe que é um órgão que tem por finalidade acompanhar e avaliar o desempenho de uma turma de alunos por meio de reuniões periódicas. Participam deste conselho os docentes que lecionam para a turma, os pais dos alunos, o orientador educacional e outros profissionais conforme o que se encontra estabelecido no regimento da escola. É notório que ele se mostra como um espaço de aprendizagem da democracia.

Encontram-se funcionando também os conselhos escolares, os quais constituem um espaço de aprendizagem participativa, democrática e de empoderamento de seus integrantes. Tais conselhos se baseiam no envolvimento efetivo e democrático da comunidade escolar e se revelam como um elemento importante e indispensável de gestão porquanto são compostos por representantes dos diversos segmentos da escola e exercem funções consultivas, deliberativas e fiscalizadoras relacionadas às questões pedagógicas, administrativas e financeiras. Na medida em que os conselhos escolares avançam como meio de construção da comunidade escolar a democracia vai sendo construída ativamente e vivenciada em processos reais.

Outro colegiado existente em quase todas as escolas é o grêmio estudantil cuja diretoria é escolhida por meio de votação. Os grêmios possuem autonomia para fazer propostas à escola bem como sugerir e organizar atividades em seu interior. Eles se apresentam como um recurso capaz de estimular a atitude de iniciativa por parte dos alunos e reforçar o sentimento de estar integrado na vida escolar. Além de desenvolverem atividades no âmbito interno das escolas os alunos filiados ao grêmio também as realizam no ambiente externo desde há muito tempo nas formas de campanhas, mutirões e movimentos.

A elaboração do projeto político pedagógico da escola apresenta-se como outra tarefa de realização coletiva. Este projeto tem por finalidade organizar o trabalho pedagógico da escola em sua totalidade tendo em vista o tipo de aluno que se pretende formar para viver em uma sociedade democrática. A sua construção bem como a sua revisão ocorrem de maneira democrática e têm a capacidade de gerar procedimentos para lidar com os conflitos, o corporativismo, o autoritarismo, a burocratização e as relações competitivas além de 
reduzir os efeitos do trabalho fragmentado e de amainar o controle hierárquico.

Além da existência desses conselhos tem-se também a eleição de diretores das escolas. Estas eleições começaram em nosso país juntamente com o início do processo de redemocratização e nos dias de hoje as escolas pertencentes à maioria dos Estados brasileiros escolhem seus diretores por meio de eleições (LUDWIG, 2019). Esta forma de seleção é uma decorrência do imperativo constitucional referente à gestão democrática da educação que é confirmada na Lei de Diretrizes e Bases da Educação Nacional e no Plano Nacional de Educação. Os milhares de diretores escolhidos pelo voto, desde há um bom tempo, vêm contribuindo para o exercício da democracia e do aprendizado da cidadania ativa no interior das escolas.

Duas experiências educacionais merecem ser mencionadas ainda pelas suas dimensões, alcance e expressividade. Uma delas se refere ao modelo pedagógico implantado por Paulo Freire na Prefeitura de S. Paulo entre os anos de 1989 a 1992. Este modelo, concretizado em poucos anos, visou a democratização da gestão, a construção coletiva de um currículo interdisciplinar e a formação de cidadãos críticos e responsáveis. Alguns princípios orientaram o modelo em questão dentre os quais cabe destacar a construção coletiva do saber, a transformação do indivíduo em sujeito de sua própria história, o oferecimento de um espaço de organização política e o incentivo à atuação no âmbito social.

A segunda tem relação com o Movimento dos Trabalhadores Rurais sem Terra ciado na década de oitenta do século passado. Por causa da dinâmica ocupacional de áreas consideradas improdutivas as crianças e jovens acompanhantes dos adultos precisavam receber educação formal. Consequentemente seus líderes resolveram criar um setor de educação a partir do ano de 1987. Tal setor elaborou um documento (NETO, 2010) que vem orientando toda a prática educativa, o qual é composto por princípios filosóficos e princípios pedagógicos. Dentre os primeiros destacam-se a educação para a transformação social, a educação para o trabalho e a cooperação e a educação assentada em valores humanistas e socialistas. Em relação aos segundos evidenciam-se a relação entre a teoria e a prática, os conteúdos de aprendizagem socialmente úteis, a íntima conexão entre os processos educativos e políticos e, principalmente a gestão participativa, a auto-organização dos estudantes e os coletivos pedagógicos que possibilitam a todos vivenciar a democracia.

Quanto ao ensino superior nacional os expedientes empregados se mostram diferentes. Parece que as atividades de extensão são as mais comuns e frequentes. Vale ressaltar, entretanto, que a extensão universitária no Brasil tem sido vista, predominantemente, como um recurso de formação profissional e não como um instrumento

Cidadania em Ação: Revista de Extensão e Cultura, Florianópolis (SC), v.4, n.2, jul./dez. 2019. 
político, ou seja, como uma oportunidade de reflexão, de repensar as ações acadêmicas perante as demandas sociais, de meditar a respeito da assimétrica apropriação social do conhecimento e de especular sobre a necessidade de formar profissionais comprometidos com mudanças na sociedade.

Esta oportunidade está em consonância com a concepção original da extensão universitária e que se manteve no decorrer do tempo. Tal concepção pode ser verificada em um dos artigos de Paula (2013). Ao discorrer sobre a história da extensão ele menciona que seu surgimento ocorreu na década de setenta do século dezenove na Universidade de Cambridge, cujos dirigentes ofereceram cursos a diferentes regiões e segmentos sociais, ministrados por seus professores. Nesta mesma época a Universidade de Oxford organizou atividades voltadas para os bolsões de pobreza localizados na cidade de Londres, as quais se difundiram rapidamente para as regiões habitadas por operários.

O avanço da extensão com o passar dos anos alcançou muitos países do continente europeu e chegou aos Estados Unidos da América do Norte. Em diversas universidades europeias e norte americanas emergiram propostas para contemplar interesses manifestados pelos trabalhadores e torná-los mais aptos para enfrentar os efeitos maléficos do capitalismo. Em período mais recente as instituições de ensino superior também têm se aproximado do setor empresarial que possui interesses relacionados à transferência de tecnologias e à criação de novos conhecimentos utilizáveis nas organizações produtivas.

Em nosso país encontra-se registrado que as atividades de extensão universitária tiveram seu início nos primórdios do século vinte (Paula, 2013) O ponto de partida ocorreu em São Paulo, posteriormente elas floresceram no Rio de Janeiro e Minas Gerais e mais tarde vicejaram em outros Estados. Segundo Paula, na Universidade de Recife, durante os anos sessenta, emergiu de maneira explícita, efetiva e através delas, o envolvimento da Universidade com as grandes questões nacionais graças ao empenho de Paulo Freire que neste período era o responsável pelo Serviço de Extensão Universitária. Sob sua liderança este serviço se aproximou bastante dos setores populares, principalmente através de programas de alfabetização. A partir das décadas seguintes as instituições de ensino superior passaram a atender também os anseios do setor produtivo por meio da prestação de serviços e transferência de tecnologias.

Nos dias atuais muitos estabelecimentos universitários ofertam atividades de extensão. A esse respeito podemos citar como exemplos, dentre inúmeros outros, a Universidade Federal Fluminense cujos alunos do curso de enfermagem desenvolvem práticas de atenção primária á saúde bem como concretizam ações voltadas para o apoio e à

Cidadania em Ação: Revista de Extensão e Cultura, Florianópolis (SC), v.4, n.2, jul./dez. 2019. 
orientação aos cuidadores. Na Universidade do Estado de Santa Catarina o Centro de Ciências da Saúde e do Esporte promove atividades de lazer e fornece orientações sobre qualidade de vida aos idosos. Na Faculdade de Odontologia de Araraquara, município de São Paulo, realiza-se atendimento odontológico ao público oriundo dos segmentos sociais menos favorecidos. Embora essas experiências estejam prioritariamente voltadas para a aquisição de conhecimentos e aperfeiçoamento de habilidades profissionais elas se mostram consoantes ao aprendizado e ao exercício da cidadania ativa.

Ao lado das atividades de extensão encontra-se em andamento o trabalho voluntário, um exemplo típico e destacado de prática cidadã. Vale realçar que durante o ano de 2017 mais de sete milhões de brasileiros o praticaram (OLIVEIRA, 2018). Esta cifra equivale a quase quatro e meio por cento da população acima dos quatorze anos de idade. Em 2018 esta quantidade se manteve, sendo que a dedicação individual para com ele girou em torno de seis horas e meia por semana (SARINGER, 2019).

Muitas faculdades brasileiras já usaram e continuam usando o trabalho voluntário discente nos cursos de graduação. Pode ser citado como exemplo o curso de administração da Pontifícia Universidade Católica do Rio de Janeiro cujos alunos no decorrer do ano de 2010 realizaram atividades em organizações que desenvolvem projetos em prol de crianças de baixa renda, relacionados à defesa do meio ambiente, voltados à creches e aos abrigos e casas de assistência a pessoas vítimas de paralisia cerebral. Na Pontifícia Universidade Católica do Paraná, desde o ano de 2002, alunos do curso de Psicologia atuam em brinquedotecas enquanto discentes do curso de Relações Públicas atuam em diversos setores da comunidade local. Na Faculdade Evangélica de Curitiba estudantes do primeiro ano de vários cursos realizam ações nos setores de pediatria, pronto socorro e ala de queimados do hospital universitário.

Em agosto de 2017, por meio do decreto no. 9.149, o então presidente da república instituiu o Programa Nacional de Voluntariado com o objetivo de incentivar o engajamento social e a participação cidadã em ações transformadoras da sociedade. Nele encontram-se presentes um Conselho Gestor e uma Plataforma Digital para coordenar a demanda e a oferta de atividades voluntárias. No mês de setembro de 2018 surgiu a resolução no. 2 do Conselho Nacional de Educação a qual estabeleceu as diretrizes para o voluntariado no ensino superior. As justificativas apresentadas incluem o vínculo da educação com a prática social, a valorização da experiência extraescolar, a formação humana dos estudantes e o preparo para o exercício da cidadania. Os princípios da responsabilidade cívica e de engajamento com a comunidade dentre outros emergem como fundamentos. É bem provável que esta

Cidadania em Ação: Revista de Extensão e Cultura, Florianópolis (SC), v.4, n.2, jul./dez. 2019. 
resolução provoque o avanço do trabalho voluntário nas universidades. E embora o aspecto cívico seja marcante nesta resolução é sabido que o envolvimento dos estudantes com o trabalho voluntário é estimulado pelos motivos de obtenção de satisfação pessoal, oportunidade de formação profissional, aproveitamento curricular e vantagem pessoal no momento da busca pelo primeiro emprego.

Tem-se também experiências de service learning, tais como as praticadas pelos europeus e norte-americanos. A Universidade de São Paulo (ARAÚJO; ARANTES, 2010) parece que emergiu como pioneira nesta área, pois desde os primórdios do funcionamento do campus leste, os mais de mil alunos ingressantes no primeiro ano de diversos cursos são orientados em trabalhos de resolução de problemas incidentes nos temas relativos a qualidade de vida, educação e saúde e culturas locais dentre outros. A partir desses trabalhos já foram criadas várias dezenas de grupos que elaboraram uma elevada quantidade de projetos os quais foram postos em prática nos bairros pobres da região. Dentre eles destacamse os relacionados ao acompanhamento pré-natal de gestantes, qualidade de vida de pessoas adultas, fornecimento de orientações a respeito de direitos e leis de acessibilidade, desenvolvimentos de atividades esportivas e culturais, formação de líderes locais, grupos infantis de leitura, orientação sexual de adolescentes, preparação para o mercado de trabalho e ações de conscientização política.

A Universidade de Brasília (SILVA, 2012) também faz uso do service learning através dos denominados Projetos de Extensão de Ação Contínua que têm por objetivo o desenvolvimento da comunidade local. Tais projetos agregam os temas pertinentes à cultura, direitos humanos, educação, justiça, meio ambiente, saúde, tecnologia e trabalho e dele podem participar alunos de todos os cursos em funcionamento.

Da mesma forma emprega o service learning a Escola de Administração Pública e de Empresas da Fundação Getúlio Vargas do Rio de Janeiro (SILVA, 2012) por meio do Programa de Gestão de Projetos Comunitários. Estes projetos são realizados em parceria com as comunidades ligadas às pastorais da Arquidiocese local e têm por objeto um curso de gestão de projetos comunitários voltado para a finalidade de ampliar a capacidade de ação da própria comunidade, ou seja, de fazer com que ela seja capaz de gerir projetos próprios de maneira participativa.

Em nosso país há ainda uma atividade cívica muito significativa, criada por nós brasileiros que é o Projeto Rondon. Sua geração teve início no ano de 1966 a partir de uma reunião onde estiveram presentes dirigentes e professores das universidades sediadas no então Estado da Guanabara e representantes do Ministério da Educação. No ano seguinte foi

Cidadania em Ação: Revista de Extensão e Cultura, Florianópolis (SC), v.4, n.2, jul./dez. 2019. 
organizada uma equipe composta por dois professores e trinta universitários que viajaram para o Estado do Amazonas e para o território federal de Rondônia com a finalidade de conhecer mais de perto estas regiões durante quase um mês. Após o retorno deles emergiu um movimento universitário favorável ao prosseguimento dessas viagens. Em 1968 mais de seiscentos universitários se dirigiram para os Estados do Amazonas e do Mato Grosso segundo o portal do Ministério da Defesa.

O Projeto Rondon tem por objetivos proporcionar uma oportunidade de conhecimento das peculiaridades da realidade brasileira, oferecer um espaço para o exercício da cidadania ativa e contribuir para o desenvolvimento sustentável das comunidades carentes dentre outros. Em 2015 foi legalmente estabelecido que o projeto deve se voltar prioritariamente para regiões que apresentam baixo índice de desenvolvimento humano e exclusão social e áreas isoladas do território nacional, tais como o norte e o nordeste do país. Para cumprir esta diretriz são constituídas anualmente equipes multidisciplinares compostas por dois professores e oito alunos, os quais dispõem de quinze dias para concretizar nos municípios selecionados o que anteriormente planejaram. Destaque-se que no decorrer desses mais de cinquenta anos do Projeto Rondon aproximadamente quatrocentos mil alunos tiveram a chance de atuar em prol dos setores desfavorecidos da nossa sociedade.

\section{CONSIDERAÇÕES FINAIS}

Em termos de síntese cabe reviver em primeiro lugar o conceito de cidadania inicialmente exposto. A opção adotada centrou-se a figura do cidadão ativo que se encaixa nas concepções pós-moderna, comunitarista e marxista, apesar das particularidades que lhes são próprias embora não explicitadas. O significado de cidadania ativa foi brevemente elucidado para justificar a posição assumida de que qualquer proposta voltada para o preparo do cidadão não deve amparar-se em pressuposições ou subentendidos relativos à ideia de cidadania.

Fazendo uma análise comparativa é possível notar que tanto nos Estados Unidos da América do Norte quanto em países europeus e também no Brasil estão sendo colocados em prática alguns expedientes bastante apropriados e efetivos à formação dos estudantes universitários com vistas ao exercício da cidadania ativa. Percebe-se, entretanto que, ao contrário do que ocorre nos Estados Unidos e na Europa, inexiste em nosso país um compromisso explícito e ostensivo por parte das instituições de ensino superior quanto a esta formação verifica-se que ela não possui a vitalidade e a abrangência que são notórias nestas duas localidades. 
Desde há muito tempo educadores progressistas defendem que o ensino, em todos os níveis, não deve voltar-se apenas para o pleno desenvolvimento do aluno e nem mirar somente a aquisição das competências necessárias ao exercício profissional. Estas intenções fazem parte do aspecto adaptador do ensino. Porém ele possui também um aspecto transformador, ou seja, de ação do sujeito na sociedade com vistas a imprimir nela as modificações necessárias favoráveis ao bem comum, principalmente em relação aos setores menos favorecidos que as integram. No âmbito de uma comunidade democrática a única maneira aceitável e congruente de lutar por mudanças é por meio do exercício da cidadania ativa. 


\section{REFERÊNCIAS}

ARAÚJO, P.; ARANTES, V. Aprendizaje Basado em Problemas y Construcción de Ciudadanía: El Projecto de la Universidad de São Paulo. In Aprendizaje Servicio y Responsabilidad Social de las Universidades. Miguel Martinez (Ed.), Barcelona: Ediciones Octaedro, 2010.

ARAÚJO, C.; SILVA, V.; DURÃES, S. Processo de Bolonha e Mudanças Curriculares na Educação Superior: Para que Competências? Educação e Pesquisa, São Paulo, v. 44, 2018.

BOLAND, J. Student Participation in Shared Governance: A Means of Advancing Democractic Values? Tertiary Education and Management, Springer, 2005.

BOLSEIRA, C. A Gestão do Voluntariado. In: Empreendedorismo Social em Portugal. Cristina Parente Edição, Faculdade de Letras da Universidade do Porto, 2014.

CHIZZOTTI, A.; CASALI, A. O Paradigma Curricular Europeu das Competências. Cadernos de História da Educação, v. 11, n. 1, jan./jun. 2012.

COMISSÃO EUROPEIA/EACEA/Eurydice, 2005. A Educação para a Cidadania nas Escolas da Europa - 2005. Relatório Eurydice. Luxemburgo: Serviço das Publicações da União Europeia. Disponível em: file:///C:/Users/Notebook/Downloads/cidpt1\%20(4).pdf. Acesso em 8 de jun. 2019.

COMISSÃO EUROPEIA/EACEA/Eurydice, 2012. A Educação para a Cidadania nas Escolas da Europa - 2012. Relatório Eurydice. Luxemburgo: Serviço das Publicações da União Europeia. Disponível em http://eacea.ec.europa.eu/education/euridyce. Acesso em 8 de jun. 2019.

COMISSÃO EUROPEIA/EACEA/Eurydice, 2017. A Educação para a Cidadania nas Escolas da Europa - 2017. Relatório Eurydice. Luxemburgo: Serviço das Publicações da União Europeia. Disponível em:

file:///C:/Users/Notebook/Downloads/EC0418086PTN.pt\%20(1).pdf. Acesso em 8 de jun. 2019.

DOTE, L. College Students Helping America: Corporation for National and Community Service. Disponível em: https://eric.ed.gov/?id=ed494174. Acesso em: 2 jun. 2019.

EDUCATION COMMISION OF THE STATES. 50-State Comparison: Civic Education Policies, 2016. Disponível em: http://ecs.org/citizenshio-education-policies. Acesso em 15 jun. 2019.

EDWARDS, B. Who is Being Served? The Impact of Student Volunteering on Local Community Organizations. Non Profit and Voluntary Sector Quarterly, v. 30, n.3, September, 2001. 
FREIRE, M. Razões para o Ensino Superior Ativar o Serviço Comunitário. Revista Forges, v. 5, n.2, 2017.

HOLDSWORTH, C.; QUINN, J. Student Volunteering in Englidh Higher Education. Studies in Higher Education, v. 35, issue 1, 2010.

HOSKINS, B. Competences for Learning to learn and Active Citizenship: Different Currencies or two Sides of the Same Coin? In: European Journal of Education, 2, feb., 2010.

LUDWIG, A. A Reforma do Ensino Médio e a Formação Para a Cidadania. Campinas: Pontes, 2019.

McCOWAN, T. Opening Spaces for Citizenship in Higher Education: Three Initiatives in English Universities. Studies in Higher Education, v. 37, issue 1, 2012.

NAVAL, C. Universidad y Consciencia Cívica Algumas Experiências Fructíferas: Service Learning y Campus Compact. Aprendizaje Servicio y Responsabilidad Social de las Universidades. Miguel Martinez (Ed.), Barcelona: Ediciones Octaedro, 2010.

NETO, M. Educação do MST. In. Oliveira, D. A.; Duarte, A.M.C.; Vieira, L.M.F. Trabalho, Profissão e Condição Docente. Belo Horizonte: UFMG, 2010. Disponível em: http://www.gestrado.net.br/pdf/246.pdf. Acesso em 23 jul. 2019.

OLIVEIRA, N. Brasileiros Realizam Trabalho Voluntário. Disponível em: http://agenciabrasil.ebc.com.br/node/1116832. Acesso em 4 nov. 2019.

PAULA, J. A. A Extensão Universitária: História, Conceito e Propostas. Interfaces Revista de Extensão, v. 1, n.1, jul./nov. 2013.

PERRENOUD, P. Escola e Cidadania. Porto Alegre, Artmed, 2005.

PINSKY, J.; PINSKY, C. (org.). História da Cidadania. São Paulo: Contexto, 2003.

RODRIGUES, Maria. A Estratégia de Lisboa e Suas Implicações Para a Reforma Institucional da União Europeia. Revista do Serviço Público, v. 54, n. 3, 2003.

SARINGER, G. Milhões de Brasileiros Fazem Trabalho Voluntário. Disponível em: https://noticias.r7.com/noticias. Acesso em 9 abr. 2019.

SCHLIERF, K. La Transferencia de Tecnología Participativa desde la Universidad: Hacia un Cambio Tecnológico. In: MARTINEZ, M. (Ed.). Aprendizaje Servicio y responsabilidade Social de las Universidades. Barcelona: Ediciones Octaedro, 2010.

SILVA, N. Contribuições da Metodologia Service Learning Para o Ensino de Responsabilidade Social em Cursos de Graduação em Administração. Dissertação de Mestrado. Fundação Getúlio Vargas, Rio de Janeiro, 2012. 
TAPIA, M. Calidad Acadêmica y Responsabilidad Social: El Aprendizaje Servicio Como Puente Entre dos Culturas Universitarias. In: MARTINEZ, M. (Ed.), Aprendizaje Servicio y Responsabilidad Social de las Universidades. Barcelona: Ediciones Octaedro, 2010.

WARREN, J. Does Service Learning Increase Student Learning? Michigan Journal of Community Service Learning, v. 18, n. 2, 2012.

WATSON, D. International Perspectives on Civic Engagement. New York: Routledge, 2011.

WESTHEIMER, J. Ensino Para a Ação Democrática. Educação e Realidade. Porto Alegre: v. 40, n. 2, abr./jun. 2015. 